I hope, therefore, that Prof. Prestwich will accept my assurance that I had no intention of suggesting that he was in any way indebted to Pbillips. I regret also that my reference to the Weald is not sufficiently clear; I said: "It is open to question whether the Weald ever had the character of a mountain-region." The question which I was considering was whether stones are ever worn by the action of torrents so as to produce a groove in one side, and I placed the remarks quoted above in a footnote. Of course the Weald must at some time have been a region of comparative elevation; but consilering the nature of the materials of which it was composed, and that denudation must have gone on during the period of gradual elevation, it appeared to me permissible to doubt whether it was ever a mountain-region in the sense in which, for instance, the district of Snowdon is a mountain-region; that is to say, a region giving birth to numerous torrents.

But in any case the argument in my paper would not be affected; and $I$ have certainly no wish to raise a controversy on a matter in regard to which Prof. Prestwich knows far more than I do.

Thorndale, Crayen Road, Readiva.

O. A. Shrubsole,

\title{
MOUNTAIN-MAKING BY TENSION.
}

SIR,-Mr. Vaughan "Laving stated a new theory to account for the inequalities of the Earth's Surface," and this theory being dependant upon the tensile strength of the Earth's crust, I suggested that be should favour us with some proof that the outer shell of the Earth is sufficiently strong to do the work demanded of it. $\mathrm{He}$ observed in his first paper, "It obviously follows that the outer shell exerts a squeezing force upon the interior, and by compressing the mass into a smaller volume increases its density." In my communication to this MAGAzINe ${ }^{2}$ I pointed out that no tensile stress that the Earth's crust could stand would be sufficient to compress the materials of the interior of the Earth, stating in effect that if the outer shell is assumed to be 30 miles thick, and of the tensile strength of steel, it could not exert a pressure of half a ton per square inch upon the interior without fracturing.

Mr. Vaughan now says that he does not rely upon decrease of volume due to pressure, but " upon the transference of material from beneath a surface of great pressure to below a surface upon which the pressure is much less." This is not very different to what I understood of his theory from his first paper, and my calculation was given merely to show what an exaggerated view Mr. Vaughan held of the compressive powers of a contracting crust. Mr. Vaughan's theory, so far as I can understand it, appears to be this :-Mountain Ranges are produced by the differential tensile stresses of a shrinking crust causing a local flattening of the Earth's curvature, and thus compelling a flow of material from where the crust is strong enough to prevent, to where it is weak enough to permit of, bulging. Now, on the assumption that a shell of steel 30 miles thick represents the tensile strength of the contracting crust-an exceedingly liberal

1 Geol. Mag. 1894, p. 264.

2 Ibid. p. 414. 
estimate-the maximum effect, leaving out of account internal friction, would be equal to raising a column of rock 1000 feet above the normal of the Earth's surface; but, when we come to consider a local contraction of the crust, we have an exceedingly complex problem to deal with. Each section of the spherical shell, such as we have assumed, would initially possess tensile strength sufficient to put the same pressure per square inch upon the interior of the sphere that the whole shell would; but, as the area became flattened by contraction, its power of compression would become proportionally less. Taking this into consideration, together with internal friction, in small areas the elevatory effect by transference of material would become infinitesimal.

If this reasoning be true, and I believe it to be so, MountainMaking by Tension is an impossibility. It will not account for either the shape, height, bulk, or linear direction of Mountain Ranges as we know them, much less the compression and folding most of them have undergone. We are thus thrown back upon some theory of compression would we account for mountainstructure as seen in Nature.

Before concluding, I would point out that, in addition to these quantitative deficiencies, Mr. Vaughan's theory seems to involve a mechanical contradiction. If the tensile strength of the contracting crust were great enough to do the required work, a strong enough anchorage would be needed at the boundaries; whereas by the hypothesis this is the weak part, otherwise it could not be elevated by material forced to flow under it from below the contracting area. It seems to me very like the case of a man trying to lift himself up by pulling at the chair he is sitting upon.

Park Corner, Blundell Sands, Liverpool.

T. Meliand Reade.

\section{OPITUARY. \\ WILLIAM TOPLEY, F.R.S., F.G.S.}

BorN March 13Th, 1841. Died September 30Th, 1894.

(With a Portrait.)

William Toplex was born at Greenwich, on March 13th, 1841 ; and after gaining his early education at local schools, he received, during the years 1858-61, the valuable scientific and practical training of the Royal School of Mines.

In 1862 he was appointed an Assistant Geologist on the Geological Survey, when Murchison was Director-General, and Ramsay was Local Director for Great Britain. He then commenced field-work under the guidance of Dr. (now Professor) Le Neve Foster, who, with others, was engaged in the Survey of the Wealden area. There he was initiated into the methods of geological mapping among the changeful Hastings Beds, at Mayfield and other places between Burwash and Lindfield, to the south of Ashdown Forest. There, too, in course of time, he gained a detailed knowledge of the Cretaceous and Neocomian formations, and his interest was aroused in questions of Physical Geology, to which for many years he gave particular attention. 